\title{
ОЦЕНКА ЭФФЕКТИВНОСТИ ПРИМЕНЕНИЯ БАКТЕРИОФАГОВ В КОМПЛЕКСЕ ПОДДЕРЖИВАЮЩЕЙ ТЕРАПИИ У ОНКОЛОГИЧЕСКИХ ПАЦИЕНТОВ, ПОЛУЧАЮЩИХ ТЕРАПИЮ ИНГИБИТОРАМИ ЕGFR
}

\author{
Абдеева Элина Ильдусовна \\ Орлова Людмила Олеговна \\ Филиппова Юлия Алексеевна
} студенты

Научный руководитель: Орлова Екатерина Вадимовна к.м.Н., доцент ФГАОУ ВО Первый МГМУ им. И.М. Сеченова Минздрава России (Сеченовский Университет)

Аннотация: согласно современным данным, частота развития кожной токсичности (КТ) на фоне лечения различных видов рака ингибиторами тирозинкиназных рецепторов эпидермального фактора роста (EGFR, epidermal growth factor receptor) достигает 90-95\%. Наиболее распространенными методами коррекции акнеподобных проявлений КТ является назначение системной антибиотикотерапии, что крайне нежелательно для пациентов с метастатическим поражением печени. В данной статье описываются альтернативные методы коррекции акнеподобных проявлений КT анти-EGFR терапии на основе изучения состава кожной микробиоты. Предполагается, что использование бактериофагов в комплексе поддерживающей терапии $\mathrm{y}$ онкобольных со временем станет одним из стандартных методов лечения.

Ключевые слова: колоректальный рак, рецептор к эпидермальному фактору роста, Панитумумаб, кожная токсичность, бактериофаги, фаговая терапия. 


\title{
EFFICACY EVALUATION OF PHAGE-BASED PRODUCTS AS PART OF SUPPORTING THERAPY OF ONCOLOGICAL PATIENTS RECEIVING EGFR INHIBITORS
}

\author{
Abdeeva Elina Ildusovna \\ Orlova Lyudmila Olegovna \\ Filippova Yulia Alexeevna \\ Scientific adviser: Orlova Ekaterina Vadimovna
}

\begin{abstract}
According to current data, the incidence of dermatological toxicity (DT) associated with treatment by EGFR (epidermal growth factor receptor) inhibitors reaches $90-95 \%$. The most common methods of correcting acne-like manifestations of DT are the prescription of systemic antibiotic therapy, which is highly undesirable in patients with metastatic liver injury. This article describes alternative methods for correcting acne-like manifestations of CT anti-EGFR therapy based on the study of the composition of the skin microbiota. It is assumed that the use of bacteriophages in the complex of maintenance therapy in cancer patients will eventually become one of the standard methods of treatment.
\end{abstract}

Key-words: colorectal cancer, epidermal growth factor receptor, panitumumab, dermatologic toxicity management, skin toxicity, bacteriophage, phage therapy.

Актуальность исследования. Настоящим достижением онкоиммунологии последних десятилетий стало внедрение в клиническую практику таргетной противоопухолевой терапии [1, с. 142 ; 2, с. 374]. К основным мишеням данных препаратов относятся факторы роста, являющиеся проангиогенными цитокинами, необходимыми для неоангиогенеза при опухолевой прогрессии и метастазировании [3, с. 542]. При видах рака, сопровождающихся активирующими мутациями в гене рецептора к эпидермальному фактору роста (EGFRs), используются препараты, ингибирующие сигнальный путь этого рецептора. Особое внимание следует уделить тому, что при метастатическом колоректальном раке(мКРР), который занимает 3 место в структуре онкозаболеваемости во всем мире, с успехом используются блокаторы EGFR (в случае мутации в RAS) [4, с. 204; 5, с. 87]. Однако, к сожалению, блокада рецепторов к EGFR приводит к нарушению таких физиологических процессов, как регуляция роста эпидермиса, дифференцировки, а также заживление ран (рис.1). 


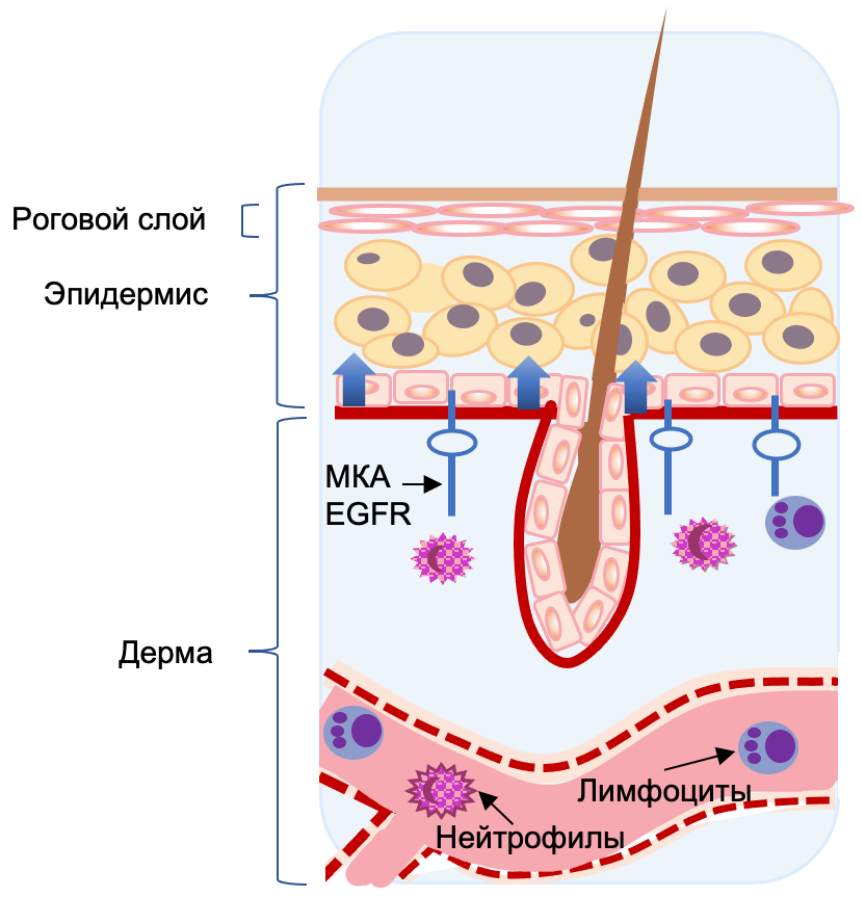

Рис. 1. Роль EGFRs в регуляции физиологических процессов кожи

Так, наиболее частым нежелательным явлением со стороны кожных покровов является угреподобная сыпь, зачастую осложненная вторичной пиодермией. [6, с. 282 ; 7, с. 227; 8, с. 135]. Данное осложнение приводит к ухудшению качества жизни пациентов и вынуждает прерывать лечение основного заболевания [9, с. 160] (рис.2).

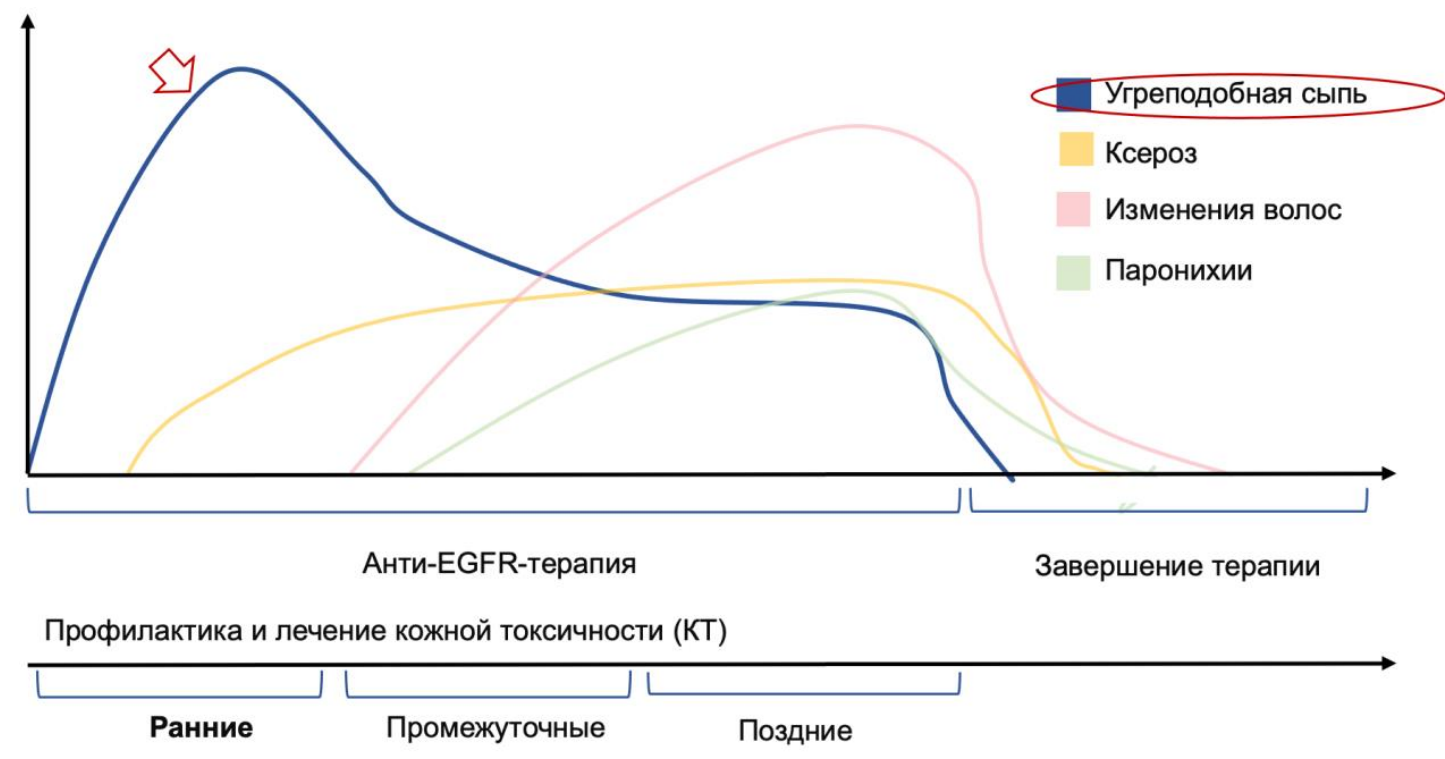

Рис. 2. Особенности кожных осложений в зависимости от стадии анти-EGFR терапии 
В случае развития подобных осложнений, согласно клиническим рекомендациям, необходимо назначать системную антибиотикотерапию и местное применение кортикостероидов [10, с. 32]. Такой вид лечения крайне нежелателен у пациентов с метастатическими поражениями печени [11, с. 1840].

Целью нашего исследования является разработка альтернативных способов коррекции данных кожных осложнений. Нами была произведена оценка эффективности применения препаратов на основе бактериофагов в качестве альтернативы системной антибиотикотерапии (в связи с тем, что они не оказывают системной токсичности и не подавляют рост представителей нормофлоры). Задачи исследования включали в себя: выявление характера изменений состава кожной микробиоты у пациентов с кожной токсичностью в виде акнеформных высыпаний, определение чувствительности кожной микробиоты к бактериофагам in vitro и проведение сравнительной оценки эффективности системной антибиотикотерапии и местного использования бактериофагов в коррекции кожной токсичности у пациентов, получающих анти-EGFR терапию.

Материалы и методы. В исследование были включены мужчины в возрасте 39-48 лет, получающие терапию Панитумумабом по поводу мКРР.

Данная когорта испытуемых была разделена на две подгруппы: первая включала в себя 24 пациента, получающих стандартную схему антибиотикотерапии (ССТ), вторая - 20 испытуемых, коррекция кожных осложнений которым проводилась отечественным препаратом на основе бактериофагов «Фагодерм» (СТФ). Достоверных различий между изначальными параметрами в разных группах не было. Степень тяжести кожной токсичности в обеих группах была от легкой до умеренной.

Оценка тяжести кожных осложнений проводилась согласно клиническим рекомендациям на основании определения площади поверхности пораженной кожи, а также наличия дополнительных клинических проявлений в виде сильного жжения, зуда, лихорадки.

Посев содержимого пустул на стандартизированные среды проводился на момент включения в испытание и спустя две недели от начала терапии, продемонстрировав преобладание Stafylococcus aureus y обеих групп испытуемых. Статистическая обработка данных проводилась с использованием программы PASW Statistics 18. Уровень достоверности определялся как $\mathrm{p} \leq 0,05$ во всех сравнениях. 
Результаты. В обеих группах развитие кожной токсичности достигало $40 \%$, локализация пустул на лице и верхней части туловища, $85 \%$ и $83 \%$ соответственно группам сравнения. В обеих группах преобладали Staphylococcus aureus (78-92\%) и Escherihia Coli (5-9\%). При сравнительной оценке эффективности антибактериальной терапии на 5-е сутки, регресс высыпаний $\geq 70 \%$ был отмечен у $76 \%$ пациентов из группы ССТ, в группе СТФ - у $80 \%$ (рис.3)

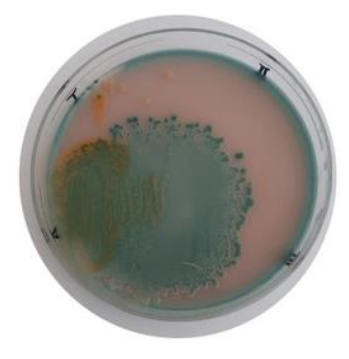

a

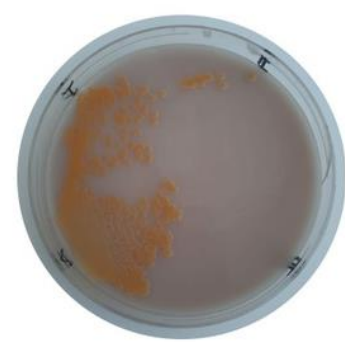

б

Рис. 3. Посев содержимого пустул в группе «СТФ» на момент включения в испытание (а) и спустя 2 недели после фаговой терапии (б)

Ограничения исследования. Необходимо отметить, что на достоверность результатов безусловно повлияло вынужденное редуцирование дозы и последующая отмена антибиотикотерапии у $33 \%$ испытуемых первой группы вследствие повышения печеночных трансаминаз (АЛТ,АСТ) в 1,5-2 paзa.

Выводы. Включение в схему поддерживающей терапии препаратов на основе бактериофагов является эффективным и может использоваться в качестве монотерапии при легких проявлениях и в комплексной терапии кожной токсичности средней и тяжелой степени.

Дальнейшие исследования, безусловно, необходимы для применения этого метода в практике, но в то же время, рассмотрение возможности внедрения этого метода в профиль лечения таких пациентов является перспективным направлением онкологии, дерматологии и смежных специальностей.

\section{Список литературы}

1. S.Ramakrishnan, V.Anand and S. Roy. Vascular Endothelial growth factor signaling in hypoxia and Inflammation. J Neuroimmune Pharmacol. 9(2): 142-160 (2014) 
2. Lucy L., Matthew S., Barbara J. Bacteriophage Therapy: Clinical Trials and Regulatory Hurdles. Front Cell Infect Microbiol. 8(1), 374-376 (2018)

3. Huon JF et al. Phages versus Antibiotics To Treat Infected Diabetic Wounds in a Mouse Model: a Microbiological and Microbiotic Evaluation. mSystems. 2020/ 10;5(6):e00542-20.

4. Kifelew L. et al. Efficacy of phage cocktail AB-SA01 therapy in diabetic mouse wound infections caused by multidrug-resistant Staphylococcus aureus. BMC Microbiol. 2020/ 9;20(1):204.

5. Lacouture $\mathrm{M}$ et al. Dermatologic Toxicity Occurring During Anti-EGFR Monoclonal Inhibitor Therapy in Patients With Metastatic Colorectal Cancer: A Systematic Review. Clin Colorectal Cancer. 2018 Jun;17(2):85-96. doi: 10.1016/j.clcc.2017.12.004 ( 2017)

6. Helena Parracho, Ben Burrowes et al. The role of regulated clinical trials in the development of bacteriophage therapeutics. J Mol Genet Med. 2012; 6: 279286.

7. Akhil K Seth, Matthew R Geringer, Khang T Nguyen et al. Bacteriophage therapy for Staphylococcus aureus biofilm-infected wounds: a new approach to chronic wound care. Plast Reconstr Surg. 131(2):225-34 (2014)

8. P. Domingo-Kalap et al. Back to the future: bacteriophages as promising therapeutic tools. HLA 87(3):133-40 (2016)

9. Ishak R.S., Aad S.A., Kyei A., Farhat F.S. Cutaneous manifestations of anti-angiogenic therapy in oncology: Review with focus on VEGF inhibitors. Critical Reviews in Oncology/Hematology. 90(2), 152-164 (2014)

10. Артамонова Е.В., Мазнюк Л.В. Кожная токсичность блокаторов EGFR (основанная на клинической исследовании цетуксимаба). Онкология, гематология и радиология. 34(1), 30-35 (2012)

11. S. O'Flaherty, R.P. Ross. Potential of the Polyvalent Anti-Staphylococcus Bacteriophage K for Control of Antibiotic-Resistant Staphylococci from Hospitals. Appl Environ Microbiol. 2005 Apr; 71(4): 1836-1842 